\title{
Accuracy of diagnosis and health service codes in identifying frailty in Medicare data
}

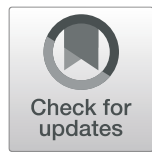

Natalia Festa', Sandra M. Shi ${ }^{2,3}$ and Dae Hyun Kim ${ }^{2,3,4^{*}}$ (D)

\begin{abstract}
Background: Capturing frailty within administrative claims data may help to identify high-risk patients and inform population health management strategies. Although it is common to ascertain frailty status utilizing claims-based surrogates (e.g. diagnosis and health service codes) selected according to clinical knowledge, the accuracy of this approach has not yet been examined. We evaluated the accuracy of claims-based surrogates against two clinical definitions of frailty.

Methods: This cross-sectional study was conducted in a Health and Retirement Study subsample of 3097 participants, aged 65 years or older and with at least 12-months of continuous fee-for-service Medicare enrollment. We defined 18 previously utilized claims-based surrogates of frailty from Medicare data and evaluated each against clinical reference standards, ascertained from a direct examination: a deficit accumulation frailty index (FI) (range: 01) and frailty phenotype. We also compared the accuracy of the total count of 18 claims-based surrogates with that of a validated claims-based FI model, comprised of 93 claims-based variables.

Results: $19 \%$ of participants met clinical criteria for the clinical frailty phenotype. The mean clinical FI for our sample was 0.20 (standard deviation 0.13). Hospital Beds and associated supplies was the claims-based surrogate associated with the highest clinical FI (mean FI 0.49). Claims-based surrogates had low sensitivity ranging from 0.01 (cachexia, adult failure to thrive, anorexia) to 0.38 (malaise and fatigue) and high specificity ranging from 0.79 (malaise and fatigue) to 0.99 (cachexia, adult failure to thrive, anorexia) in discriminating the clinical frailty phenotype. Compared with a validated claims-based $\mathrm{Fl}$, the total count of claims-based surrogates demonstrated lower Spearman correlation with the clinical Fl $(0.41$ [95\% Cl 0.38-0.44] versus 0.59 [95\% Cl, 0.56-0.61]) and poorer discrimination of the frailty phenotype (C-statistics $0.68[95 \% \mathrm{Cl}, 0.66-0.70]$ versus $0.75[95 \% \mathrm{Cl}, 0.73-0.77]$ ).

Conclusions: Claims-based surrogates, selected according to clinical knowledge, do not accurately capture frailty in Medicare claims data. A simple count of claims-based surrogates improves accuracy but remains inferior to a claims-based Fl model.
\end{abstract}

Keywords: Frailty, Frailty phenotype, Older adult, Medicare administrative data

\footnotetext{
* Correspondence: dkim12@bwh.harvard.edu

${ }^{2}$ Division of Gerontology, Department of Medicine, Beth Israel Deaconess

Medical Center, 1620 Tremont Street, Boston, MA 02120, USA

${ }^{3}$ Hinda and Arthur Marcus Institute for Aging Research, Hebrew SeniorLife, Boston, MA, USA

Full list of author information is available at the end of the article
}

(c) The Author(s). 2020 Open Access This article is licensed under a Creative Commons Attribution 4.0 International License, which permits use, sharing, adaptation, distribution and reproduction in any medium or format, as long as you give appropriate credit to the original author(s) and the source, provide a link to the Creative Commons licence, and indicate if changes were made. The images or other third party material in this article are included in the article's Creative Commons licence, unless indicated otherwise in a credit line to the material. If material is not included in the article's Creative Commons licence and your intended use is not permitted by statutory regulation or exceeds the permitted use, you will need to obtain permission directly from the copyright holder. To view a copy of this licence, visit http://creativecommons.org/licenses/by/4.0/. The Creative Commons Public Domain Dedication waiver (http://creativecommons.org/publicdomain/zero/1.0/) applies to the data made available in this article, unless otherwise stated in a credit line to the data. 


\section{Background}

Frailty is a major risk factor for adverse health outcomes among older adults, including falls, hospitalization, disability, institutionalization, and death [1-3]. The societal impact of frailty is projected to increase as its associated adverse outcomes accrue with population aging [4]. Due to its considerable individual and social costs, there is a critical need to reliably measure and monitor the epidemiologic burden of frailty [5]. As prevalent frailty increases with population aging, a standardized approach to its measurement is a precondition to informed health policy. Accurate recognition is similarly important to the primary and secondary prevention of this syndrome $[6,7]$. In the absence of routine clinical assessment of frailty, administratively-derived measures that are well calibrated to clinical screening instruments will underpin its reliable identification and measurement.

Within administrative data, the identification of frail individuals is complicated by the absence of specific diagnosis codes to designate frailty [8]. This has resulted in the triangulation of frailty status according to the related but separate proxies of disability and comorbidity burden [1]. As such, there is increasing interest in measuring frailty through claims-based surrogates, including diagnosis, health-service, and procedural codes [9-11]. A series of claims-derived, model-based algorithms to identify frailty have been developed [12-19]. With comparable frequency, researchers have also attempted to identify frailty through the purposeful selection of administrative surrogates, as informed by clinical knowledge [16, 20-26]. For example, one such approach empirically segmented Medicare beneficiaries according to claims-based diagnoses that were inferred to represent frailty $[25,26]$. This latter approach is often favored due to parsimony and ease of implementation $[8,25,26]$.

Despite the accelerated development of instruments with which to capture frailty in administrative data, the performance of claims-based surrogates has not yet been evaluated against clinical frailty definitions. This study evaluates the accuracy of diagnosis and health service codes in identifying frailty, as defined by the frailty phenotype and a deficit-accumulation frailty index (FI) from a clinical examination, using Medicare data linked to the Health and Retirement Study (HRS). We then compare the performance of the selected administrative surrogates with that of a validated claims-based FI [12, 17, 27].

\section{Methods}

\section{Study population}

The HRS is a representative survey of communitydwelling adults in the United States, aged 50-years and older. The HRS longitudinally measures the health, cognitive, and functional status of its respondents [9-11]. All members of the HRS cohort are surveyed directly or by proxy on a biennial basis. All HRS subjects provide written informed consent prior to each interview, as well as oral consent in the presence of trained study professionals. The HRS is sponsored by the National Institute on Aging (grant NIA U01A6009740) and conducted by the University of Michigan with Institutional Review Board Approval.

This cross-sectional study includes 3097 communitydwelling HRS respondents who were aged $\geq 65$-years, randomly selected to undergo clinical assessment of physical performance, and had 12 months of continuous fee-forservice Medicare enrollment prior to the 2008 HRS interview. In over $80 \%$ of participants, HRS data were linked to Medicare fee-for-service data. We used inpatient, outpatient, skilled nursing facility, home health, carrier, and durable medical equipment files that include International Classification of Diseases (ICD, version 9), Current Procedural Terminology (CPT), and Healthcare Common Procedure Coding System (HCPCS) codes collected in the year preceding the HRS interview. This study was approved by the Institutional Review Board at the Brigham and Women's Hospital in Boston, Massachusetts.

\section{Clinical definitions of frailty}

Our analysis utilized two clinical reference standards, the categorical frailty phenotype and the quantitative deficit-accumulation frailty index (FI). The measures for each reference standard were ascertained via direct clinical assessment of HRS participants by trained study professionals, as detailed within HRS survey data. The clinical frailty phenotype was defined according to the biologic syndrome model, with HRS-adapted criteria [28]. This model characterizes frailty according to the 5 domains of unintentional weight loss, exhaustion, low physical activity, slowness, and weakness (Supplementary Table S1) [29]. Individuals with impairments in $\geq 3$ domains were considered frail, in 1-2 domains, pre-frail, and, in no domains, robust. We employed the standard deficit accumulation approach to calculate our quantitative clinical reference standard, the FI, utilizing 43 health deficits [30, 31]. The FI (range: $0-1$ ) is the number of deficits present, divided by the total number of deficits measured (Supplementary Table S2). A higher FI score indicates a greater degree of frailty $[27,30,31]$.

\section{Claims-based surrogates of frailty: diagnosis and health service codes}

We selected 18 claims-based frailty surrogates that have commonly been applied in prior research (Table 1$)[8,25$, 26]. These claims-based surrogates represent both clinical features and consequences of frailty, which closely map onto geriatric syndromes (dementia, sensory disorders) and functional deficits (minor and severe ambulatory limitations, selfcare impairment) [19]. A surrogate measure was ascribed to 
Table 1 Claims-Based Surrogates of Frailty

\begin{tabular}{ll}
\hline Conditions Suggestive of Frailty & ICD-9/10 or HCPCS Codes \\
\hline Pressure ulcer & (ICD9) 707.0X, 707.2X, (ICD10) L89.XX \\
Cachexia & (ICD9) 799.4, (ICD10) R64 \\
Adult failure to thrive & (ICD9) 783.7, (ICD10) R62.7 \\
Muscle weakness & (ICD9) 728.87, (ICD10) M62.81 \\
Debility & (ICD9) 799.3, (ICD10) R54 \\
Difficulty in walking & (ICD9) 719.7, (ICD10) R26.2 \\
History of fall & (ICD9) V15.88, (ICD10) Z91.81 \\
Abnormality of gait & (ICD9) 781.2, (ICD10) R26.0, R26.1, R26.89, R26.9 \\
Anorexia & (ICD9) 783.0, (ICD10) R63.0 \\
Abnormal loss of weight and underweight & $($ ICD9) 783.21, 783.22 (ICD10) R63.4, R63.6 \\
Muscular wasting and disuse atrophy & (ICD9) 728.2, (ICD10) M62.50 \\
Senility without mention of psychosis & (ICD9) 797, (ICD10) R41.81 \\
Malaise and fatigue & (ICD9) 780.79, (ICD10) R53.1, R53.81, R53.83 \\
Hospital beds and associated supplies & $($ HCPCS) E0250-E0373 \\
Wheelchairs, components, and accessories & (HCPCS) E0950-E1298, E2201-E2294, E2300-E2399, E2601-E2621, K0001-K0195, K0669 \\
Accessories for oxygen delivery devices & (HCPCS) E1353-E1406 \\
Walking aids and attachments & (HCPCS) E0100-E0159 \\
Transportation services including ambulance & (HCPCS) A0021-A0999
\end{tabular}

Abbreviations: HCPCS Healthcare Common Procedure Coding System, ICD International Classification of Diseases

a participant if he or she had been assigned a particular code within the 12 months preceding the HRS interview. These claims-based surrogates were examined individually and in a total count ("count approach") (range 0-18) against clinical definitions of frailty.

\section{Claims-based frailty index: a model-based approach}

We estimated a previously validated claims-based FI $[12,17,27]$, which utilizes ICD, CPT, and HCPCS codes in Medicare claims data over a 12-month period. The selected claims-based FI has previously outperformed alternative claims-based FIs in its agreement with the clinical frailty phenotype and clinical FI [27]. The weights assigned to 93 claims-based variables in the model were estimated from a lasso penalized regression model. A SAS program to calculate this claims-based FI from the Medicare data or United States commercial insurance data is available (https://dataverse.harvard.edu/dataset.xhtml?persistentId=doi:10.7910/DVN/HM8DOI). We compared the performance of the claims-based FI model to that of the total count of claims-based surrogates in predicting clinical frailty definitions.

\section{Statistical analysis}

Analyses were performed using R version 3.6.0 and Stata version 14. We summarized population characteristics in mean and standard deviation (SD) or proportions. Because the frailty phenotype was undetermined for 827 individuals with missing measures of gait speed and grip strength, we performed a single multivariable imputation (Stata mi impute chained command) to assign the missing frailty phenotype with available information (demographic characteristics, chronic conditions, and self-reported health and functional status).

We estimated the proportion of individuals with each claims-based surrogate of frailty. For each claims-based surrogate, we calculated the associated mean and standard deviation (SD) of the clinical FI. We then determined sensitivity, specificity, positive predictive value (PPV), and negative predictive value (NPV) for the clinical frailty phenotype. We next examined the distribution of the total count of claims-based surrogates of frailty, the "count approach." For each threshold of the count approach (i.e., an individual is considered frail if the individual has claims-based surrogates of frailty equal to or more than this threshold), we calculated the mean and SD of the clinical FI, as well as the sensitivity, specificity, PPV, and NPV for the clinical frailty phenotype. As a comparison, we examined the performance of the claims-based FI model ("model-based approach") at various cutpoints. An optimal cutpoint was defined as the threshold that achieved the highest combined sensitivity and specificity. In addition, we compared the count approach and the model-based approach by estimating Spearman correlation with the clinical FI and C-statistics for the clinical frailty phenotype. We determined the 95\% confidence intervals (CIs) of Spearman correlation and C-statistics through 1000 bootstrap resampling. 


\section{Results}

\section{Characteristics of study population}

The 3097 HRS respondents included in the analysis had a mean age of 75.7 years (SD 7.2). Women and Caucasian respondents comprised $58.1 \%(n=1798)$ and $86.6 \%$ $(n=2683)$ of the sample, respectively. The mean FI for the overall sample was 0.20 (SD 0.13). Among 2270 respondents with complete data on the components of frailty phenotype, the proportions of robust, pre-frail, and frail individuals were $21.9 \%(n=679), 40.4 \% \quad(n=$ $1252)$, and $10.9 \% \quad(n=339)$. After imputation, the corresponding proportions were $27.6 \%(n=856), 53.4 \%$ $(n=1654)$, and $19.0 \%(n=587)$, suggesting that those with missing data had more severe frailty.

\section{Claims-based surrogates of frailty}

The most prevalent claims-based surrogates were malaise and fatigue (23.9\%), transportation services including ambulance (9.7\%), abnormality of gait (7.5\%), muscle weakness (5.3\%), and accessories for oxygen use devices (4.8\%) (Table 2). Claims-based surrogates associated with the highest mean clinical FI were hospital beds and associated supplies (FI 0.49), pressure ulcer (FI 0.43), cachexia (FI 0.43), wheelchairs, components, and accessories (FI 0.41), and adult failure to thrive (FI 0.36). Claims-based surrogates were specific but not sensitive in identifying the clinical frailty phenotype. Except for malaise and fatigue (specificity 0.79), all surrogates had specificity greater than 0.90 . Surrogates with the highest sensitivity were malaise and fatigue (sensitivity 0.38 ) and transportation services including ambulance (sensitivity 0.24). At the imputed prevalence of phenotypic frailty (19\%) within our sample, the highest PPV was observed for cachexia (PPV 0.75), hospital beds and associated supplies (PPV 0.73), and wheelchairs, components, and accessories (PPV 0.63). The NPV was greater than 0.80 for all surrogates.

\section{Total count of claims-based surrogates of frailty}

The proportions of respondents whose administrative data indicated a total count of $0,1,2,3,4$, and $\geq 5$ claims-based frailty surrogates were $61.4,22.7,6.8,4.3$, 2.3, 2.6\%, respectively (Fig. 1 ). The corresponding mean clinical FI ranged from 0.16 (0 surrogates) to $0.40(\geq 5$ surrogates). The associated proportion of the clinical frailty phenotype ranged from $11.7 \%$ (0 surrogates) to $66.2 \%$ ( $\geq 5$ surrogates).

Table 2 Performance of Claims-Based Surrogates of Frailty Against Clinical Frailty Assessment in the Health and Retirement StudyMedicare Data

\begin{tabular}{|c|c|c|c|c|c|c|}
\hline \multirow[t]{2}{*}{ Claims-Based Surrogates of Frailty $^{\mathbf{a}}$} & \multirow{2}{*}{$\begin{array}{l}\text { Sample Size } \\
(\%)\end{array}$} & \multirow{2}{*}{$\begin{array}{l}\text { Clinical FI } \\
\text { Mean } \\
\text { (SD) }\end{array}$} & \multicolumn{4}{|c|}{ Clinical Frailty Phenotype } \\
\hline & & & Sensitivity & Specificity & PPV & NPV \\
\hline Hospital beds and associated supplies & $44(1.4 \%)$ & $0.49(0.14)$ & 0.06 & 0.99 & 0.73 & 0.82 \\
\hline Pressure ulcer & $39(1.3 \%)$ & $0.43(0.17)$ & 0.04 & 0.99 & 0.59 & 0.82 \\
\hline Cachexia & $<10(<0.3 \%)$ & $0.43(0.11)$ & 0.01 & $>0.99$ & 0.75 & 0.81 \\
\hline Wheelchairs, components, and accessories & $63(2.6 \%)$ & $0.41(0.15)$ & 0.09 & 0.99 & 0.63 & 0.82 \\
\hline Adult failure to thrive & $<10(<0.3 \%)$ & $0.36(0.17)$ & 0.01 & $>0.99$ & 0.57 & 0.81 \\
\hline Muscle weakness & $164(5.3 \%)$ & $0.34(0.16)$ & 0.12 & 0.96 & 0.44 & 0.82 \\
\hline Accessories for oxygen delivery devices & $149(4.8 \%)$ & $0.34(0.16)$ & 0.11 & 0.97 & 0.44 & 0.82 \\
\hline Debility & $50(1.6 \%)$ & $0.34(0.15)$ & 0.04 & 0.99 & 0.48 & 0.81 \\
\hline Difficulty in walking & $135(4.4 \%)$ & $0.32(0.15)$ & 0.10 & 0.97 & 0.44 & 0.82 \\
\hline Walking aids and attachments & $130(4.2 \%)$ & $0.32(0.14)$ & 0.10 & 0.97 & 0.47 & 0.82 \\
\hline History of fall & $56(1.8 \%)$ & $0.31(0.16)$ & 0.04 & 0.99 & 0.41 & 0.81 \\
\hline Transportation services including ambulance & $300(9.7 \%)$ & $0.31(0.16)$ & 0.24 & 0.93 & 0.46 & 0.84 \\
\hline Abnormality of gait & $231(7.5 \%)$ & $0.31(0.15)$ & 0.18 & 0.95 & 0.45 & 0.83 \\
\hline Anorexia & $15(0.5 \%)$ & $0.30(0.22)$ & 0.01 & $>0.99$ & 0.33 & 0.81 \\
\hline Abnormal loss of weight and underweight & $112(3.6 \%)$ & $0.28(0.16)$ & 0.08 & 0.97 & 0.44 & 0.82 \\
\hline Muscular wasting and disuse atrophy & $23(0.7 \%)$ & $0.28(0.12)$ & 0.02 & 0.99 & 0.39 & 0.81 \\
\hline Senility without mention of psychosis & $<10(<0.3 \%)$ & $0.26(0.21)$ & $<0.01$ & $>0.99$ & 0.33 & 0.81 \\
\hline Malaise and fatigue & $740(23.9 \%)$ & $0.25(0.15)$ & 0.38 & 0.79 & 0.30 & 0.84 \\
\hline
\end{tabular}

Abbreviations: FI frailty index, HCPCS Healthcare Common Procedure Coding System, ICD International Classification of Diseases, NPV negative predictive value, PPV positive predictive value, $S D$ standard deviation

${ }^{a}$ Claims-based surrogates of frailty were defined as occurrence of the respective codes in a 12-month period in any of the inpatient, outpatient, skilled nursing facility, home health, carrier, and durable medical equipment datasets 
$100 \%$

$80 \%$

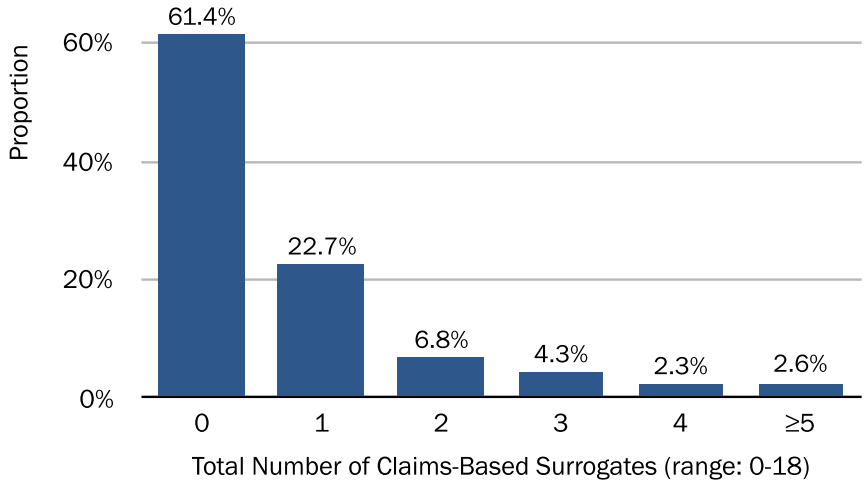

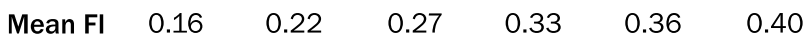

Frailty phenotype (\%) $\quad 11.7 \% \quad 20.4 \% \quad 32.9 \% \quad 43.6 \% \quad 59.2 \% \quad 66.2 \%$

Fig. 1 Classification of Frailty by Total Count of Claims-Based Frailty Surrogates in the Health and Retirement Study-Medicare Data. Abbreviations: $\mathrm{Fl}$, frailty index

An increasing count of claims-based frailty surrogates corresponded to a decrease in sensitivity, from $0.62(\geq 1$ surrogates) to 0.09 ( $\geq 5$ surrogates), and an increase in specificity, from 0.67 ( $\geq 1$ surrogates) to 0.99 ( $\geq 5$ surrogates), in discriminating the clinical frailty phenotype (Table 3). An optimal cutpoint of $\geq 1$ surrogate achieved the highest combined sensitivity (0.62) and specificity (0.67) for the count approach. At the prevalence of the frailty phenotype $(19.0 \%)$ in the study population, the total count of claims-based surrogates showed a modest PPV of 0.31 (cutpoint $\geq 1$ ) to 0.66 (cutpoint $\geq 5$ ). The NPV was greatest for a threshold of $\geq 1$ surrogate (0.88).

\section{Comparison with a model-based approach}

The proportions of respondents with claims-based FI scores $<0.15,0.15-0.19,0.20-0.24,0.25-0.29,0.30-0.34$, and $\geq 0.35$ were $52.7,26.9,10.7,5.5,2.0$, and $2.3 \%$, respectively (Fig. 2). The associated mean clinical FI ranged from 0.14 for those with a claims-based FI score $<0.15$ to 0.46 for those with a claims-based FI score $\geq 0.35$. The proportion of subjects meeting clinical criteria for the frailty phenotype increased in accordance with claims-based FI scores, ranging from $8.7 \%$ for those with a claims-based FI score $<0.15$ to $75.7 \%$ those with a claims-based FI score $\geq 0.35$.

The Spearman correlation with the clinical FI was lower for the count approach (correlation coefficient 0.41; 95\% CI 0.38-0.44) than for the claims-based FI model (correlation coefficient 0.59 ; 95\% CI 0.56-0.61). The count approach demonstrated poorer discrimination (C-statistic
Table 3 Performance of Total Count of Claims-Based Surrogates of Frailty versus a Model-Based Claims-Based Frailty Index

Against Clinical Frailty Assessment in the Health and Retirement Study-Medicare Data

\begin{tabular}{|c|c|c|c|}
\hline \multirow{2}{*}{$\begin{array}{l}\text { Threshold } \\
\text { to Define } \\
\text { Frailty }\end{array}$} & \multirow{2}{*}{$\begin{array}{l}\text { Positive } \\
\text { for Frailty } \\
\mathrm{N}(\%)\end{array}$} & \multirow{2}{*}{$\begin{array}{l}\text { Clinical FI } \\
\text { Mean } \\
\text { (SD) }\end{array}$} & Clinical Frailty Phenotype \\
\hline & & & nsitivity Specificity PPV \\
\hline
\end{tabular}

A. Total count of claims-based surrogates of frailty (range: $0-18)^{\text {a }}$

$\begin{array}{lllllll}\geq 1 & 1196(38.6) & 0.26(0.15) & 0.62 & 0.67 & 0.31 & 0.88 \\ \geq 2 & 494(16.0) & 0.32(0.16) & 0.38 & 0.89 & 0.45 & 0.86 \\ \geq 3 & 284(9.2) & 0.36(0.15) & 0.26 & 0.95 & 0.54 & 0.85 \\ \geq 4 & 151(4.9) & 0.38(0.15) & 0.16 & 0.98 & 0.63 & 0.83 \\ \geq 5 & 80(2.6) & 0.40(0.16) & 0.09 & 0.99 & 0.66 & 0.82\end{array}$

B. Model-based claims-based frailty index (range: $\mathbf{0 - 1})^{\mathbf{b}}$

$\begin{array}{lllllll}\geq 0.15 & 1464(47.3) & 0.26(0.14) & 0.76 & 0.59 & 0.30 & 0.91 \\ \geq 0.20 & 632(20.4) & 0.33(0.15) & 0.47 & 0.86 & 0.44 & 0.87 \\ \geq 0.25 & 302(9.8) & 0.37(0.15) & 0.30 & 0.95 & 0.58 & 0.85 \\ \geq 0.30 & 133(4.3) & 0.44(0.15) & 0.16 & 0.99 & 0.72 & 0.83 \\ \geq 0.35 & 70(2.3) & 0.46(0.16) & 0.09 & 0.99 & 0.76 & 0.82\end{array}$

Abbreviations: $F /$ frailty index, NPV negative predictive value, $P P V$ positive predictive value, $S D$ standard deviation

The optimal cutpoint of the count approach for frailty phenotype was $\geq 1$, which achieved a sensitivity of 0.62 and a specificity of 0.67

${ }^{\text {b}}$ The optimal cutpoint of CFI for frailty phenotype was $\geq 0.17$, which achieved a sensitivity of 0.66 and a specificity of 0.72 
$100 \%$

$80 \%$

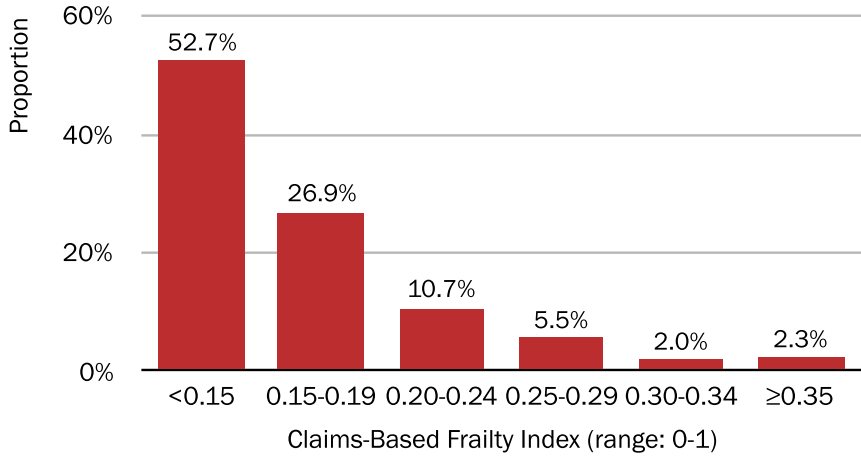

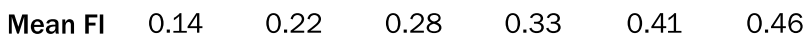

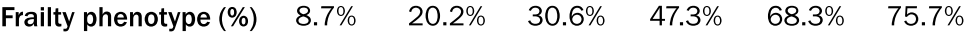

Fig. 2 Classification of Frailty by a Claims-Based Frailty Index Model in the Health and Retirement Study-Medicare Data. Abbreviations: Fl, frailty index

0.68; 95\% CI 0.66-0.70) of the clinical frailty phenotype than did the claims-based FI model (C-statistic 0.75; 95\% CI 0.73-0.77) (Fig. 3). An optimal cutpoint for the claimsbased FI model of $\geq 0.17$ achieved the highest combined sensitivity (0.66) and specificity (0.72) in discriminating the clinical frailty phenotype.

\section{Discussion}

Although certain claims-based surrogates (hospital beds and associated supplies; pressure ulcer; cachexia; wheelchairs, components, and accessories; and adult failure to thrive) appropriately identified Medicare beneficiaries with a moderate-to-severe clinical FI (mean FI >0.35), only a minority $(<3 \%)$ of the population had been assigned those codes. Similarly, these surrogates demonstrated low sensitivity $(0.01-0.38)$ and high specificity (0.80-1.00) in discerning the clinical frailty phenotype. Our findings suggest that claims-based surrogates that have been selected according to clinical expertise are suboptimal in identifying frail older adults within Medicare data. While the novel count approach improved sensitivity and specificity for the frailty phenotype, it underperformed a claims-based FI model.

Our selected claims-based surrogates of frailty represent either clinical manifestations or consequences of frailty that are recognizable by clinicians and, as such, have been commonly utilized in prior research. The most common claims-based surrogate of frailty, malaise and fatigue (23.9\% of respondents), was the most sensitive (sensitivity 0.38 ) indicator of the frailty phenotype.
The most specific indicators (specificity $\geq 0.99$ ) of the frailty phenotype (hospital beds and associated supplies; pressure ulcer; cachexia; wheelchairs, components, and accessories; adult failure to thrive) were expectedly associated with a greater mean clinical FI. The low sensitivity of these codes may reflect the lack of routine frailty screening in clinical practice or variability in the documentation of its clinical features in administrative processes [32]. Therefore, without the widespread clinical adoption and documentation of standardized frailty screening, individual claims-based surrogates are likely to remain an insufficient and inaccurate indicator of frailty status.

Despite their poor sensitivity, there was parity between the studied administrative measures and the underpinning theory of phenotypic frailty. The most common (23.9\% of respondents) and sensitive (0.35) claims-based surrogate, Malaise and fatigue, is consistent with several definitional criteria of phenotypic frailty, including weakness and exhaustion. The most specific predictors of the frailty phenotype (Hospital beds and associated supplies; Pressure ulcer; Wheelchairs, components, and accessories; Cachexia; Adult failure to thrive) maintained similar parity with the phenotypic criteria of a low level of activity, slowness, and weakness. The most specific indicators of frailty also aligned with the phenotypic criterion of weight-loss, namely, Cachexia and Adult failure to thrive. Each of the most specific indicators similarly corresponded to domains within the esteemed and proprietary JEN-Frailty Index, such as minor ambulatory 


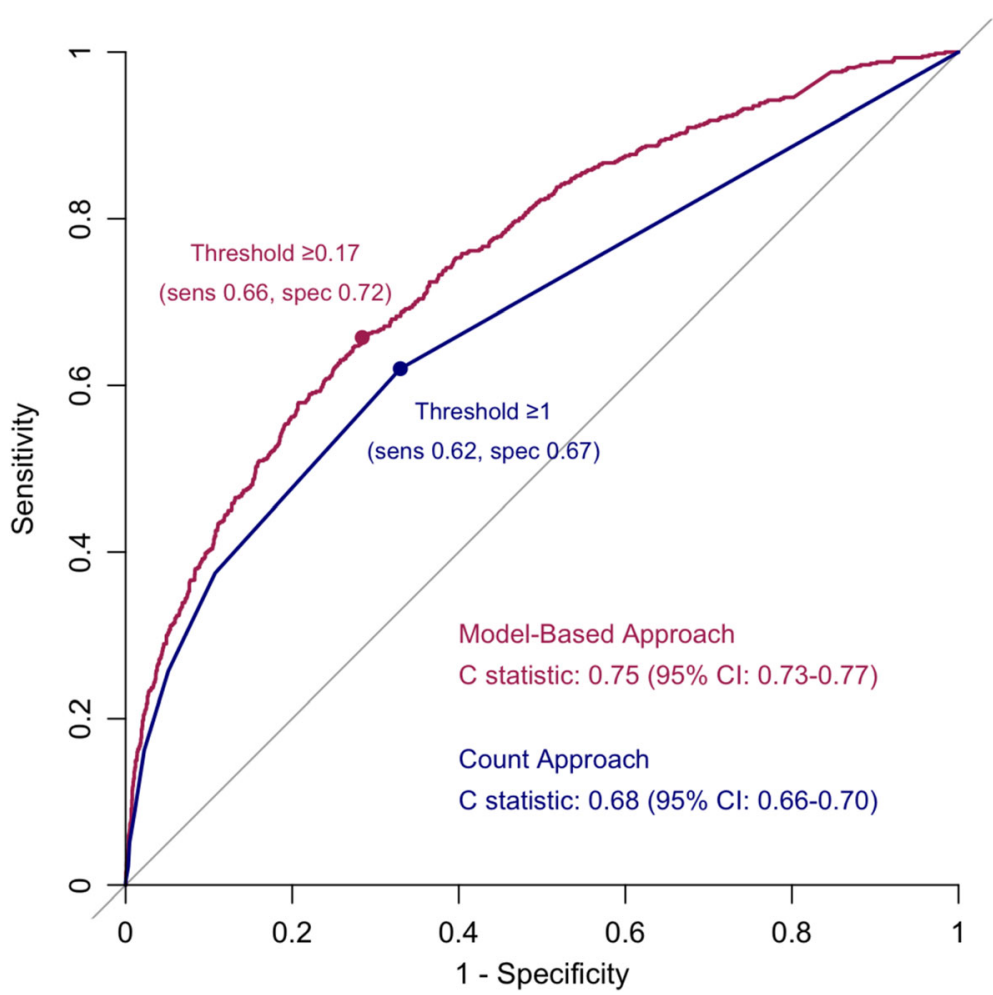

Fig. 3 Receiver Operating Characteristic Curves of Total Count of Claims-Based Frailty Surrogates (Count Approach) versus a Claims-Based Frailty Index Model (Model-Based Approach) in Identifying the Frailty Phenotype. Abbreviations: Cl, confidence interval; sens, sensitivity; spec, specificity. Legend: The count approach demonstrated a lower C-statistic than the model-based approach in identifying the frailty phenotype. The optimal cutpoint of the count approach was $\geq 1$, which achieved a sensitivity of 0.62 and a specificity of 0.67 . The optimal cutpoint of model-based approach was $\geq 0.17$, which achieved a sensitivity of 0.66 and a specificity of 0.72

limitations, severe ambulatory limitations, and self-care impairment [19].

The results of our study are informative to health services researchers and health care systems that aim to better characterize utilization and outcomes among high-need older adults through the reliable identification of frail individuals. Various efforts to identify frailty through the use of claims-based surrogates have preceded our analysis [16, 20-26]. Our results suggest that the novel count approach identifies frailty with greater accuracy than does the clinically-informed selection of claims-based surrogates. Despite its appealing parsimony and preferable performance to individual claims-based surrogates, the count approach underperformed a claims-based FI model. Considering the superior performance of the claims-based FI model, future research is needed to distinguish among recently developed and validated models [12-18]. Available claims-based FI model differ considerably with respect to their chosen reference standard (i.e. disability, frailty phenotype, or deficit-accumulation FI), data utilized for estimation and validation, and performance characteristics [27].

Our study has a few limitations. First, we assessed the performance of ICD-9 claims-based surrogates of frailty against clinical frailty definitions. Performance may be affected by associated changes in coding practice. For the purpose of future research, ICD-10 diagnoses corresponding to our analysis are summarized (Table 1). Second, we imputed the frailty phenotype for $26.7 \%$ of the study population due to missing measurements of gait speed or grip strength. The analysis of imputed data assumes that the missingness is not related to the frailty level after accounting for all measured variables, however, this missing-at-random assumption may not be satisfied. Nonetheless, exclusion of those with missing frailty data from our analysis would have resulted in a biased estimation of the performance of claims-based surrogates. Third, our study population was limited to Medicare fee-forservice beneficiaries within the HRS sample. Therefore, generalizability to beneficiaries of Medicare Advantage or a commercial insurance plan remains unclear.

\section{Conclusions}

Our study advances knowledge of the performance characteristics of claims-based surrogates in discriminating frailty status. Our results suggest that claims-based frailty surrogates offer poor sensitivity, rendering these poor screening measures at the population level. Employing a total count 
of claims-based surrogates is an efficient method that improves sensitivity, while moderately compromising specificity. Despite its attractive parsimony and simplicity, the discriminatory power of the count approach remains inferior to that of the claims-based FI model. Our results suggest that the identification of frailty through the claimsbased FI model, which assigns appropriate weights to a larger assemblage of variables, should supplant the selection of surrogates on the sole basis of clinical knowledge.

\section{Supplementary information}

Supplementary information accompanies this paper at https://doi.org/10. 1186/s12877-020-01739-w.

Additional file 1: Table S1. Clinical Reference Standard: Frailty Phenotype. Table S2. Clinical Reference Standard: Deficit Accumulation Frailty Index.

\section{Abbreviations}

HRS: Health and Retirement Study; FI: Frailty Index; SD: Standard Deviation; PPV: Positive Predictive Value; NPV: Negative Predictive Value

\section{Acknowledgements}

Not applicable.

\section{Authors' contributions}

DHK contributed to conception, design, acquisition of data, and statistical analysis. NF drafted the manuscript. NF, SS, and DHK interpreted data, critically revised the manuscript for important intellectual content. All authors have read and approved the manuscript as submitted.

\section{Funding}

This study was funded by R01AG062713 from the National Institute on Aging (NIA) and the Paul B. Beeson Clinical Scientist Development Award in Aging (K08AG051187) to DHK from NIA, American Federation for Aging Research, John A. Hartford Foundation, and Atlantic Philanthropies. SS is supported by the Harvard Translational Research in Aging Training Program (T32 AG023480). The funding sources had no role in the design, collection, analysis, or interpretation of the data, or the decision to submit the manuscript for publication.

\section{Availability of data and materials}

The Health and Retirement Study data analyzed during this study are available from the University of Michigan, pending Institutional Review Board approval.

\section{Ethics approval and consent to participate}

Our analysis is a secondary analysis of subjects in the Health and Retirement Study (HRS) cohort. The HRS is sponsored by the National Institute on Aging (grant NIA U01A6009740) and conducted by the University of Michigan. HRS subjects are enrolled and consented as per the University of Michigan with Institutional Review Board approval. All HRS subjects provide written informed consent prior to each interview, as well as oral consent in the presence of trained study professionals. The access to HRS-Medicare linked data was approved by the Centers for Medicare \& Medicare Services Privacy Board. This study was approved by the Institutional Review Board at the Brigham and Women's Hospital in Boston, Massachusetts.

\section{Consent for publication}

Not applicable.

\section{Competing interests}

DHK provides paid consultative services to Alosa Health, a nonprofit educational organization with no relationship to any drug or device manufacturers. The other authors declare no competing interests.

\section{Author details}

'Department of Internal Medicine, Massachusetts General Hospital, Boston, MA, USA. 'Division of Gerontology, Department of Medicine, Beth Israel Deaconess Medical Center, 1620 Tremont Street, Boston, MA 02120, USA. ${ }^{3}$ Hinda and Arthur Marcus Institute for Aging Research, Hebrew SeniorLife,

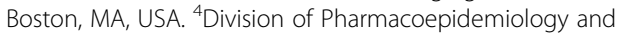

Pharmacoeconomics, Department of Medicine, Brigham and Women's Hospital, Boston, MA, USA.

Received: 29 May 2020 Accepted: 30 August 2020

Published online: 07 September 2020

\section{References}

1. Fried LP, Ferrucci L, Darer J, Williamson JD, Anderson G. Untangling the concepts of disability, Frailty, and comorbidity: implications for improved targeting and care. J Gerontol Ser A Biol Sci Med Sci. 2004;59(3):M255-63.

2. Moore G, Hartley P, Romero-Ortuno R. Health and social factors associated with a delayed discharge amongst inpatients in acute geriatric wards: A retrospective observational study. Geriatr Gerontol Int. 2018;18(4):530-7 Available from: http:// www.ncbi.n/m.nih.gov/pubmed/29230961 [cited 2020 Apr 20].

3. Xue QL. The Frailty Syndrome: Definition and Natural History. Clin Geriatr Med. 2011;27(1):1-15. https://doi.org/10.1016/j.cger.2010.08.009.

4. Buckinx F, Rolland Y, Reginster JY, Ricour C, Petermans J, Bruyère O. Burden of frailty in the elderly population: perspectives for a public health challenge. Arch Public Health. 2015;73:19 BioMed central Ltd.Available from: http://www.ncbi.nlm.nih.gov/pubmed/25866625 [cited 2020 Apr 20].

5. Morley JE, Vellas B, Abellan van Kan G, Anker SD, Bauer JM, Bernabei R, et al. Frailty consensus: A call to action. J Am Med Dir Assoc. 2013;14(6):392-7.

6. Kidd T, Mold F, Jones C, Ream E, Grosvenor W, Sund-Levander M, et al. What are the most effective interventions to improve physical performance in prefrail and frail adults? A systematic review of randomised control trials. BMC Geriatr; 2019. 19 p. 184. https://bmcgeriatr.biomedcentral.com/articles/https:// doi.org/10.1186/s12877-019-1196-x [cited 2020 Apr 20]. BioMed Central Ltd.

7. Hoogendijk EO, Afilalo J, Ensrud KE, Kowal P, Onder G, Fried LP. Frailty: implications for clinical practice and public health. Lancet. 2019;394:1365-75 Lancet Publishing Group.

8. Kim DH, Schneeweiss S. Measuring frailty using claims data for pharmacoepidemiologic studies of mortality in older adults: evidence and recommendations. Pharmacoepidemiol Drug Saf. 2014;23:891-901 Available from: http://www.ncbi.nlm.nih.gov/pubmed/24962929. John Wiley and Sons Itd; 2014 [cited 2020 Apr 20].

9. Heeringa SG, Connor J. Technical Description of the Health and Retirement Study Sample Design | Health and Retirement Study. Ann Arbor. Available from: https://hrs.isr.umich.edu/publications/biblio/5310, Ml; [cited 2020 Apr 20].

10. Fisher GG, Ryan LH. Overview of the Health and Retirement Study and Introduction to the Special Issue. Work Aging Retire. 2018;4(1):1-9 Available from: http://www.ncbi.nlm.nih.gov/pubmed/29423243 [cited 2020 Apr 20].

11. Sonnega A, Faul JD, Ofstedal MB, Langa KM, Phillips JWR, Weir DR. Cohort Profile: the Health and Retirement Study (HRS). Int J Epidemiol. 2014;43(2): 576-85 Available from: http://www.ncbi.n/m.nih.gov/pubmed/24671021 [cited 2020 Apr 20].

12. Kim DH, Schneeweiss S, Glynn RJ, Lipsitz LA, Rockwood K, Avorn J. Measuring Frailty in Medicare Data: Development and Validation of a Claims-Based Frailty Index. J Gerontol A Biol Sci Med Sci. 2018;73(7):980-7 Available from: http:// www.ncbi.nlm.nih.gov/pubmed/29244057 [cited 2020 Apr 20].

13. Faurot KR, Jonsson Funk M, Pate V, Brookhart MA, Patrick A, Hanson LC, et al. Using claims data to predict dependency in activities of daily living as a proxy for frailty. Pharmacoepidemiol Drug Saf. 2015;24(1):59-66 Available from: http://www.ncbi.n/m.nih.gov/pubmed/25335470 [cited 2020 Apr 20].

14. Cuthbertson CC, Kucharska-Newton A, Faurot KR, Stürmer T, Jonsson Funk M, Palta $\mathrm{P}$, et al. Controlling for frailty in pharmacoepidemiologic studies of older adults. Epidemiology. 2018;29(4):556-61 Available from: http://www. ncbi.nlm.nih.gov/pubmed/29621057 [cited 2020 Apr 20].

15. Segal JB, Huang J, Roth DL, Varadhan R. External validation of the claimsbased frailty index in the national health and aging trends study cohort. Am J Epidemiol. 2017;186(6):745-7 Available from: http://www.ncbi.nlm.nih. gov/pubmed/28938711 [cited 2020 Apr 20].

16. Orkaby AR, Nussbaum L, Ho Y-L, Gagnon D, Quach L, Ward R, et al. The Burden of Frailty Among U.S. Veterans and Its Association With Mortality, 2002-2012. J Gerontol A Biol Sci Med Sci. 2019;74(8):1257-64 Available from: http://www.ncbi.nlm.nih.gov/pubmed/30307533 [cited 2020 Apr 20]. 
17. Kim DH, Glynn RJ, Avorn J, Lipsitz LA, Rockwood K, Pawar A, et al. Validation of a Claims-Based Frailty Index Against Physical Performance and Adverse Health Outcomes in the Health and Retirement Study. J Gerontol A Biol Sci Med Sci. 2019;74(8):1271-6 Available from: http://www.ncbi.nlm.nih.gov/ pubmed/30165612 [cited 2020 Apr 20].

18. Davidoff AJ, Zuckerman IH, Pandya N, Hendrick F, Ke X, Hurria A, et al. A novel approach to improve health status measurement in observational claims-based studies of cancer treatment and outcomes. J Geriatr Oncol. 2013;4(2):157-65 Available from: http://www.ncbi.nlm.nih.gov/pubmed/23 795223 [cited 2020 Apr 20].

19. Kinosian B, Wieland D, Gu X, Stallard E, Phibbs CS, Intrator O. Validation of the JEN frailty index in the National Long-Term Care Survey community population: Identifying functionally impaired older adults from claims data. BMC Health Serv Res. 2018;18(1):908. https://doi.org/10.1186/s12913-0183689-2 [cited 2020 Apr 20].

20. Sternberg SA, Bentur N, Abrams C, et al. Identifying frail older people using predictive modeling. Am J Manag Care. 2012;18(10):e392-7. https:// pubmed.ncbi.nlm.nih.gov/23145847/.

21. Chrischilles E, Schneider K, Wilwert J, Lessman G, O'Donnell B, Gryzlak B, et al. Beyond comorbidity :expanding the definition and measurement of complexity among older adults using administrative claims data. Med Care. 2014;52(3 SUPPL. 2):S75-84 Available from: http://www.ncbi.nlm.nih.gov/ pubmed/24561763 [cited 2020 Apr 20].

22. Soong J, Poots AJ, Scott S, Donald K, Woodcock T, Lovett D, et al. Quantifying the prevalence of frailty in English hospitals. BMJ Open. 2015; 5(10):e008456

23. Clegg A, Bates C, Young J, Ryan R, Nichols L, Ann Teale E, et al. Development and validation of an electronic frailty index using routine primary care electronic health record data. [Erratum appears in Age Ageing. 2017 Jan 17; PMID: 28100452]. Age Ageing. 2016;45(3):353-60 Available from: https://ezp.lib.unimelb.edu.au/login?url=http://ovidsp.ovid.com/ ovidweb.cgi? $=J S \& C S C=Y \& N E W S=N \& P A G E=$ fulltext $\& D=$ med $8 \& A N=2694493$ 7 [cited 2020 Apr 20].

24. Lunney JR, Lynn J, Hogan C. Profiles of older medicare decedents. J Am Geriatr Soc. 2002;50(6):1108-12. https://doi.org/10.1046/j.1532-5415.2002 50268.x [cited 2020 Apr 20].

25. Figueroa JF, Maddox KEJ, Beaulieu N, Wild RC, Jha AK. Concentration of potentially preventable spending among high-cost medicare subpopulations. Ann Intern Med. 2017;167(10):706-13 Available from: http:// www.ncbi.n/m.nih.gov/pubmed/29049488 [cited 2020 Apr 20].

26. Joynt KE, Figueroa JF, Beaulieu N, Wild RC, Orav EJ, Jha AK. Segmenting high-cost Medicare patients into potentially actionable cohorts. Healthcare. 2017;5(1-2):62-7 Available from: http://www.ncbi.nlm.nih.gov/pubmed/2 7914968 [cited 2020 Apr 20]

27. Kim DH, Patorno E, Pawar A, Lee H, Schneeweiss S, Glynn RJ. Measuring Frailty in Administrative Claims Data: Comparative Performance of Four Claims-Based Frailty Measures in the United States Medicare Data. J Gerontol A Biol Sci Med Sci. 2019; Available from: http://www.ncbi.nlm.nih gov/pubmed/31566201 [cited 2020 Apr 20].

28. Cigolle CT, Ofstedal MB, Tian Z, Blaum CS. Comparing models of frailty: The health and retirement study. J Am Geriatr Soc. 2009;57(5):830-9 Available from: http://www.ncbi.nlm.nih.gov/pubmed/19453306 [cited 2020 Apr 20].

29. Fried LP, Tangen CM, Walston J, Newman AB, Hirsch C, Gottdiener J, et al. Frailty in older adults: evidence for a phenotype. J Gerontol Ser A Biol Sci Med Sci. 2001;56(3):M146-57.

30. Rockwood K, Mitnitski A. Frailty in relation to the accumulation of deficits. J Gerontol S A Biol Sci Med Sci. 2007;62:722-7 Gerontological Society of America.

31. Searle SD, Mitnitski A, Gahbauer EA, Gill TM, Rockwood K. A standard procedure for creating a frailty index. BMC Geriatr. 2008;8(1):24. https://doi. org/10.1186/1471-2318-8-24 [cited 2020 Apr 20].

32. Walston J, Bandeen-Roche K, Buta B, Bergman H, Gill TM, Morley JE, et al. Moving Frailty Toward Clinical Practice: NIA Intramural Frailty Science Symposium Summary. J Am Geriatr Soc. 2019;67(8):1559-64 Available from: http://www.ncbi.nlm.nih.gov/pubmed/31045254 [cited 2020 Apr 20].

\section{Publisher's Note}

Springer Nature remains neutral with regard to jurisdictional claims in published maps and institutional affiliations.

Ready to submit your research? Choose BMC and benefit from:

- fast, convenient online submission

- thorough peer review by experienced researchers in your field

- rapid publication on acceptance

- support for research data, including large and complex data types

- gold Open Access which fosters wider collaboration and increased citations

- maximum visibility for your research: over $100 \mathrm{M}$ website views per year

At BMC, research is always in progress.

Learn more biomedcentral.com/submissions 